\title{
THE EFFECT OF APPLE SEED STRATIFICATION WITH GROWTH REGULATORS ON BREAKING THE DORMANCY OF SEEDS, THE GROWTH OF SEEDLINGS AND CHLOROPHYLL FLUORESCENCE
}

\author{
Krzysztof GÓRNIK*, Mieczysław GRZESIK, Regina JANAS, Edward ŻURAWICZ, \\ Ewa CHOJNOWSKA, Renata GÓRALSKA \\ Research Institute of Horticulture \\ Konstytucji 3 Maja 1/3, 96-100 Skierniewice, Poland \\ Received: October 2017; Accepted: April 2018
}

\begin{abstract}
The aim of the study was to shorten the period of breaking dormancy in apple seeds and to improve the growth of the seedlings of 'Gold Milenium', 'Ligol' and 'Szampion'. The whole seeds were removed from fruits directly after the harvest and were subjected to stratification $\left(3{ }^{\circ} \mathrm{C}\right.$ for 90 days in darkness) in distilled water or an aqueous solutions of $500 \mathrm{mM}$ salicylic acid (SA), $10^{-3} \mathrm{M}$ jasmonic acid (JA), gibberellin $\mathrm{A}_{3}\left(\mathrm{GA}_{3}\right)$ and 6-benzylaminopurine (BAP) at $250 \mathrm{mg} \cdot \mathrm{dm}^{-3}$ and $100 \mathrm{mg} \cdot \mathrm{dm}^{-3}$, respectively. Growth regulators were applied separately or in a mixture containing SA, JA, GA 3 and BAP. The germinability and seed germination rate, seedlings growth, chlorophyll content index and the maximum quantum efficiency of Photosystem II ( $\mathrm{Fv} / \mathrm{Fm})$ were investigated. The obtained results revealed that stratification in water positively affected the dormancy removal in 'Gold Milenium', 'Ligol' and 'Szampion' seeds. Application of $\mathrm{SA}, \mathrm{GA}_{3}$, BAP, JA during seed stratification additionally stimulated the seeds' germination rate as well as the growth of seedlings, index of chlorophyll content and maximum PSII efficiency (Fv/Fm). The most pronounced results were obtained after the seed stratification in $\mathrm{GA}_{3}$ alone or in a mixture containing SA, $\mathrm{GA}_{3}$, BAP and JA. Due to such a treatment, the germination of 'Ligol' seeds increased by $40 \%$ and they germinated faster in comparison to the control seeds. Such treatments also promoted the growth of seedlings, chlorophyll content and maximum quantum efficiency of Photosystem II (Fv/Fm). The present study indicates that the application of $\mathrm{GA}_{3}$ or the mixture of SA, $\mathrm{GA}_{3}, \mathrm{BAP}$ and JA during the stratification of seeds is an effective method to increase and accelerate the germination of seeds and juvenile seedlings' growth in order to shorten the apple breeding cycle. Further studies are needed to optimize the appropriate concentration of growth regulators applied simultaneously during seeds stratification.
\end{abstract}

Keywords: apple seeds, dormancy removal, seed germination, stratification, growth regulators

\section{INTRODUCTION}

Apple breeding programs are focused on the introduction of more valuable cultivars than those already existing (Sansavini et al. 2005). There is a great interest to shorten the breeding cycle. It can be reduced by forcing seedling growth, grafting on dwarfing rootstocks, and by selection of a short juvenile period (Røen 1994). It also concerns the germination of seeds that should be fast with high percentage, uniformity, health status and further fast growth of seed- lings. To assure rapid and uniform germination and development of fully normal seedlings, the dormancy of the seeds must be sufficiently removed (Røen 1994). However, the mature apple seeds are in a state of deep dormancy (Wyzińska 1978; Ranjan \& Lewak 1994). They are able to germinate after a period or after-ripening process under moist-cold conditions of so-called cold stratification (Żarska-Maciejewska $\&$ Lewak 1976). The optimum temperature range for the removal of dormancy in apple seeds is $2-6^{\circ} \mathrm{C}$, and 75-90 days at such temperatures are normally 
required when the seeds are treated outside the fruit (Seeley \& Damavandy 1985; Røen 1994).

Some plant growth regulators, like gibberellins, cytokinin (6-benzylaminopurine), jasmonic or salicylic acid, also take part in removing apple seed dormancy (Ranjan \& Lewak 1994). Gibberellins are known as growth-promoting hormones that are involved in several processes during the development of plants, such as shoot growth, flower development, dormancy release and seed germination (Hilhorst \& Karssen 1992; Sińska 1989; Linkies \& Leubner-Metzger 2012). Jasmonic acid also stimulates germination of dormant apple seeds (Yildiz et al. 2007). Similarly, the role of cytokinins in the removal of embryonic dormancy in apple seeds is evidenced by not only the changes in the activity of endogenous hormones but also by their effects on germination of isolated embryos (Zhang \& Lespinasse 1991). Salicylic acid (SA) can be associated with the regulation of seed dormancy and enhancing seed germination by reducing oxidative damages (Chitnis et al. 2014). However, the effect of exogenous SA on seed germination largely depends on the concentration. It is assumed that the proposed methods allow for the development of universal breaking dormancy of apple seeds for breeding program, which can help reduce the production costs of genetic materials and shorten the breeding cycle.

The aim of the present study was to shorten the period of breaking dormancy in apple seeds and to accelerate the juvenile growth of plants of the three cultivars: 'Gold Milenium', 'Szampion' and 'Ligol'. For the purpose to improve apple seeds germination, stratification in distilled water or aqueous solutions of salicylic acid (SA), jasmonic acid (JA), gibberellin $\mathrm{A}_{3}\left(\mathrm{GA}_{3}\right)$ and 6-benzylaminopurine (BAP) applied separately or simultaneously in a mixture was investigated. The effect of above treatments was characterized by seeds germinability and germination rate as well as seedling growth, the index of chlorophyll content and maximum PSII efficiency ( $\mathrm{Fv} / \mathrm{Fm})$.

\section{MATERIALS AND METHODS}

\section{Plant material}

The research was conducted on apple (Malus domestica) seeds and seedlings of early-maturing
'Gold Milenium', medium early maturing 'Szampion' and late-maturing 'Ligol'. Apple seeds were collected in autumn from fruit harvested in the Experimental Orchard of the Research Institute of Horticulture in Skierniewice. The received seeds were dormant. The experiments were conducted in the three successive years of 2013-2015. Each year constitutes one repetition of the experiment.

\section{Stratification and germination of apple seeds}

Controlled stratification was performed in a growth chamber, at a constant temperature $\left(3^{\circ} \mathrm{C}\right)$ for 90 days, in the darkness. The whole seeds (with seed coats) were placed in $9 \mathrm{~cm}$ diameter Petri dishes (50 seeds per dish in three replicates), on two layers of filter paper (Alfa Chem Labolatoria) of a diameter of $85 \mathrm{~mm}$ (with a pH 7.0 and a weight $250 \mathrm{~g} \cdot \mathrm{m}^{-2}$ ) moistened with $7 \mathrm{ml}$ of distilled water or an aqueous solutions of $500 \mathrm{mM} \mathrm{SA}, 10^{-3} \mathrm{M} \mathrm{JA} \mathrm{GA}_{3}$ and BAP at 250 and $100 \mathrm{mg} \cdot \mathrm{dm}^{-3}$, respectively. The above concentrations were chosen as the optimal in the previously conducted experiments. The solutions of growth regulators were not replenished or exchanged during stratification. After harvesting, the seeds were stored in paper bags at $3{ }^{\circ} \mathrm{C}$ until use. A seed was regarded as germinated when the radicle emerged from the pericarp. Germinated seeds were counted every day to estimate the percentage of germinability and germination rate during the 90 days of stratification.

\section{Dynamics of seedlings' growth}

After stratification, the germinating seeds were sown individually in the cells of plastic multi-pots containing mixture of peat and sand $(1: 1, \mathrm{v} / \mathrm{v})$. The multi-pots were transferred to the growth chamber set at $20^{\circ} \mathrm{C}$ in $100 \mu \mathrm{mol} \cdot \mathrm{m}^{-2} \cdot \mathrm{sec}^{-1}$ white light emitted by SON-T AGRO $400 \mathrm{~W}$ lamps. All plants were grown in long-day conditions (16 hours light, 8 hours dark) and with $60 \%$ air relative humidity. Plant height was measured from the soil surface to the top of the plant, at 4-week intervals. At each measurement, 10 individuals in the middle rows were measured in three replicates. The measurements were conducted till the end of August.

\section{Chlorophyll content index}

Chlorophyll content index (CCI) measured at the stage of 6 fully developed leaves was evaluated nondestructively using portable Minolta SPAD-502 
chlorophyll meter (Konica Minolta, Japan) and expressed in SPAD units (Grzesik \& RomanowskaDuda 2014). Five readings were obtained from individual leaves.

\section{Chlorophyll fluorescence of intact leaf}

The measurements of the maximum quantum efficiency of Photosystem II were carried out on fully expanded leaves using a pulse-modulated Fluorescence Monitoring System (FMS-1; Hansatech Instruments Ltd., Norfolk, UK) operated in the $\mathrm{Fv} / \mathrm{Fm}$ mode, according to the manufacturer's instruction. Before each measuring time, the leaves were dark-adapted for at least 20 min to allow all reaction centers to open and minimize the fluorescence associated with the energization of the thylakoid membrane. The fiber optic of the FMS-1 was positioned using the PPF/temperature leaf clip at a $60^{\circ}$ angle from the upper surface of the leaf, and the distance between the fiber optic and the leaf surface was kept constant for all measurements. The parameters of chlorophyll fluorescence: maximum fluorescence $(\mathrm{Fm})$, and variable fluorescence $\mathrm{Fv}(\mathrm{Fm}-\mathrm{Fo})$, were measured in the dark-adapted leaves using leaf clips. Initial fluorescence (Fo) was measured at PPFD $<0.05 \mu \mathrm{mol} \cdot \mathrm{m}^{-2} \cdot \mathrm{s}^{-1}$, followed by a saturating pulse to determine the maximum fluorescence emission in the absence (Fm) of quenching was $3000 \mathrm{mmol} \cdot \mathrm{m}^{-2} \cdot \mathrm{s}^{-1}$. The intensity of saturation pulses to determine the maximum fluorescence emission in the absence $(\mathrm{Fm})$ of quenching was $1800 \mathrm{mmol} \cdot \mathrm{m}^{-2} \cdot \mathrm{s}^{-1}$. The maximum quantum efficiency of Photosystem II ( Fv/Fm) in the dark-adapted state was considered as a useful measurement of photosynthetic performance of plants and as stress indicators. Maximum photochemical efficiency of PSII was estimated by the equation: $\mathrm{Fv} / \mathrm{Fm}=(\mathrm{Fm}-\mathrm{Fo}) / \mathrm{Fm}$. The fluorescence measurements were conducted on second or third apical leaf received from ten plants. The mean of each fluorescence parameter was obtained from twenty readings.

\section{Statistical analyses}

The experiment for the determination of the number and dynamics of germinated seeds, seedlings' growth, chlorophyll content index and maximum quantum efficiency of Photosystem II (Fv/Fm) was repeated three times. Results concerning all the mentioned parameters were analyzed using analysis of variance. The differences between the means were estimated by the Duncan multiple range test at a significance level of $p=0.05$. Additionally, standard deviation bars are presented on the graphs. Dynamics of seeds germination presented in the graphs were expressed as average \pm the least significant difference (LSD).

\section{RESULTS AND DISCUSSION}

The presented results in Fig. 1 showed that apple seed germination depended on the cultivar and the manner of stratification. Among the examined cultivars, 'Szampion' seeds germinated at the highest percentage, in the range of $88-100 \%$. Lower seed germination was observed for 'Ligol', whereas 'Gold Milenium' seeds germinated at the lowest percentage (30 to 60\%). The lowest germinability of 'Gold Milenium' seeds could be partly caused by a negative influence of germination inhibitors present in apple fruit extracts, that is, abscisic acids, chlorogenic acids, and so on (Rudnicki 1969; Kamiński 1968).

In turn, the lower percentage of 'Ligol' seeds' germination may probably be caused due to their insufficient maturity. Obviously, the differences in their germinability may also depend on cultivar properties. Previous results (data not published) showed that the percentage of seed germination depended not only on cultivar but also on the year of seed harvest (Bewley \& Black 1994).

The present study showed that stratification in water resulted in an increase of percentage of germinated seeds in comparison to control (untreated) seeds. Application of growth regulators in most cases additionally increased seeds germinability, which indicated that they are involved in dormancy release process. The most pronounced results were obtained after $\mathrm{GA}_{3}$ treatment. Due to such application germination of 'Ligol' seeds increased by $100 \%$ in comparison to the control. Lewak (2011) also demonstrated the involvement of gibberellins in the cold-mediated removal of dormancy in apple seeds. 

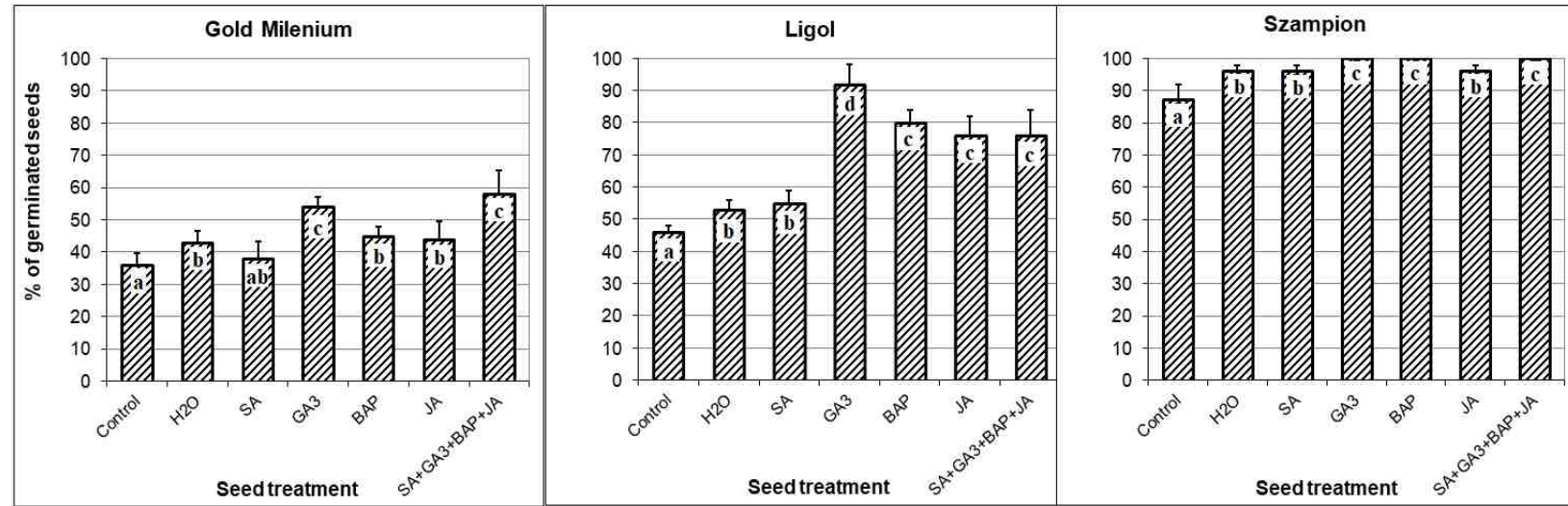

Fig. 1. Percent of germinated apple seeds on filter paper moistened with water or an aqueous solution of salicylic acid $(\mathrm{SA} ; 500 \mathrm{mM})$, jasmonic acid $\left(\mathrm{JA} ; 10^{-3} \mathrm{M}\right)$, gibberellin $\mathrm{A}_{3}\left(\mathrm{GA}_{3} ; 250 \mathrm{mg} \cdot \mathrm{dm}^{-3}\right)$, 6-benzylaminopurine (BAP; $100 \mathrm{mg} \cdot \mathrm{dm}^{-3}$ ) and in their mixture. Means with the same letter are not significantly different at $\mathrm{p}=0.05$ according to the Duncan multiply range test $(\mathrm{n}=150)$. Standard deviation bars are also presented
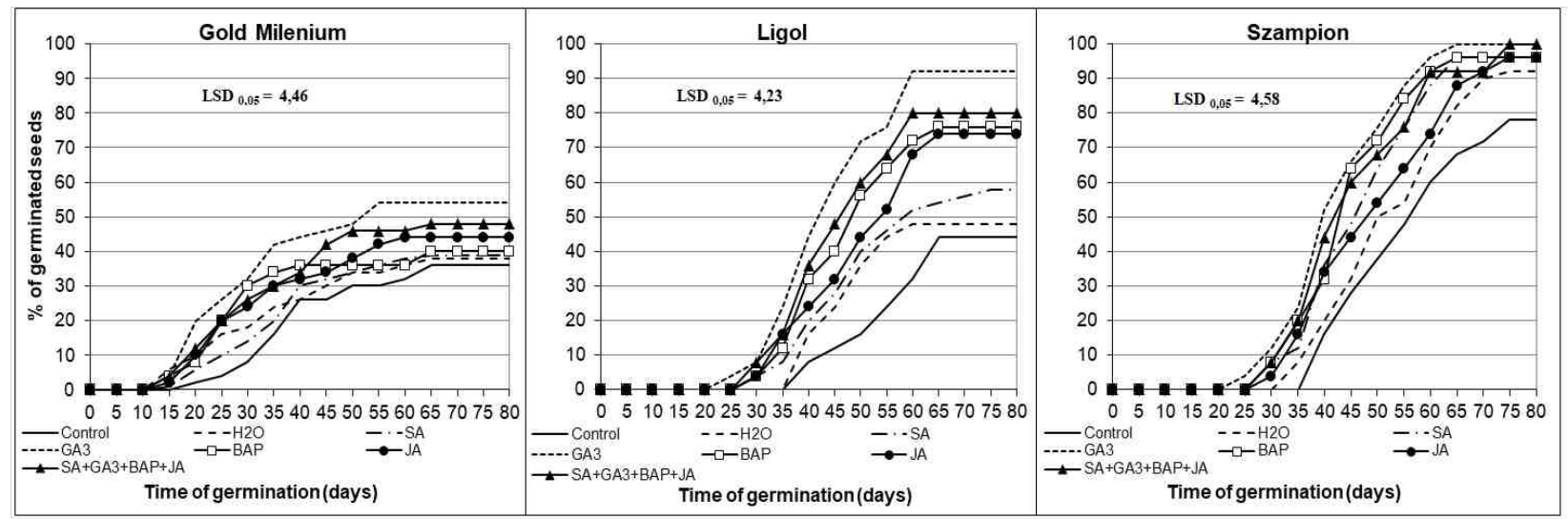

Fig. 2. Dynamics of seeds germination on filter paper moistened with $\mathrm{H}_{2} \mathrm{O}$ or an aqueous solution of salicylic acid $(\mathrm{SA} ; 500 \mathrm{mM})$, jasmonic acid $\left(\mathrm{JA} ; 10^{-3} \mathrm{M}\right)$, gibberellin $\mathrm{A}_{3}\left(\mathrm{GA}_{3} ; 250 \mathrm{mg} \cdot \mathrm{dm}^{-3}\right)$, 6-benzylaminopurine (BAP; $100 \mathrm{mg} \cdot \mathrm{dm}^{-3}$ ) and in their mixture
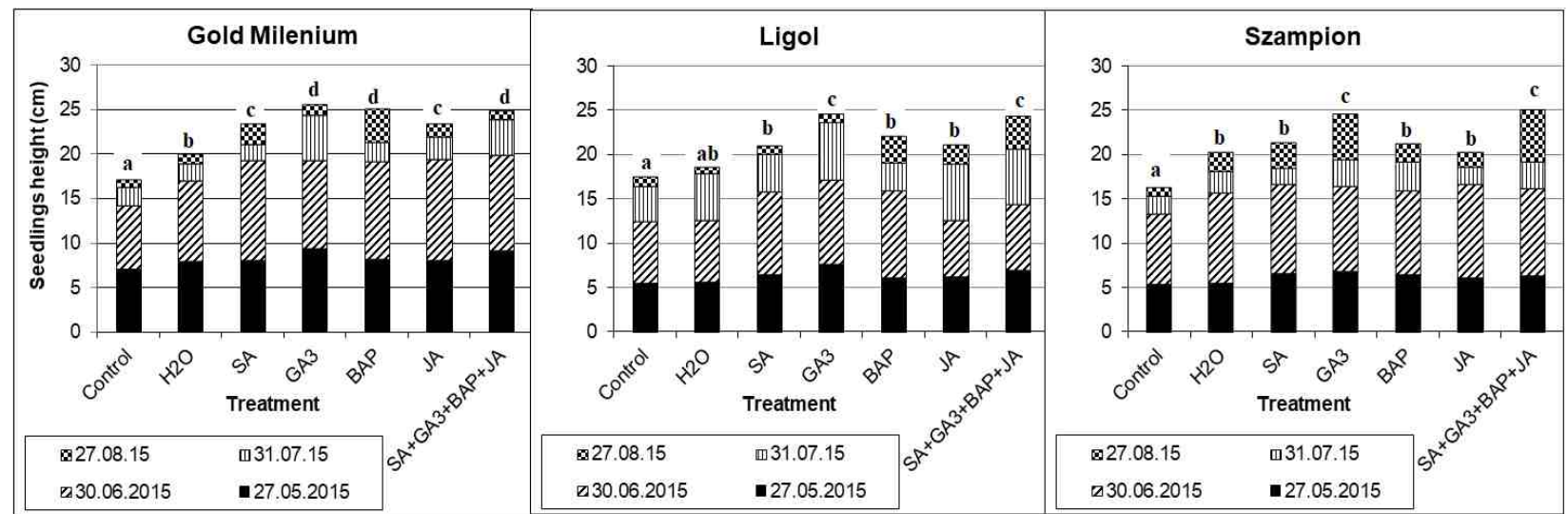

Fig. 3. Growth of seedlings derived from seeds stratified on filter paper moistened with water or in an aqueous solution of salicylic acid (SA; $500 \mathrm{mM})$, jasmonic acid $\left(\mathrm{JA} ; 10^{-3} \mathrm{M}\right)$, gibberellin $\mathrm{A}_{3}\left(\mathrm{GA}_{3} ; 250 \mathrm{mg} \cdot \mathrm{dm}^{-3}\right)$, 6-benzylaminopurine $\left(\mathrm{BAP} ; 100 \mathrm{mg} \cdot \mathrm{dm}^{-3}\right)$ and in their mixture. Means with the same letter are not significantly different at $\mathrm{p}=0.05$ according to the Duncan multiply range test $(n=30)$ 
Application of BAP during 'Ligol' stratification also greatly increased the germination of seeds. According to Zhang and Lespinasse (1991), treating non-stratified apple seeds with BAP contributed to embryo germination. Besides $\mathrm{GA}_{3}$ and $\mathrm{BAP}$ also $\mathrm{SA}$ and $\mathrm{JA}$ as single addition during stratification also increased the percentage of seeds germination. Ranjan and Lewak (1992) reported that jasmonic acid stimulated the germination of seeds, which was accompanied by increased alkaline lipase. In another study, jasmonic acid also clearly stimulated the germination of dormant apple seeds (Lewak 2011). However, some concentrations of this growth regulator inhibited the germination of apple seeds stratified for 30 and more days (Yildiz et al. 2007). In the present study, the mixture of growth regulators did not increase the germination percentage of apple seeds more than $\mathrm{GA}_{3}$.

Dynamics/rates of apple seeds germination is a very important parameter from practical point of view because it indicates whether the shortening of dormancy period takes place during stratification. In the present study, seeds subjected to stratification at $3{ }^{\circ} \mathrm{C}$ in $\mathrm{H}_{2} \mathrm{O}$ or the aqueous solutions of growth regulators germinated significantly faster than the control (untreated) seeds (Fig. 2). Stratification of seeds in $\mathrm{GA}_{3}$ at a concentration of $250 \mathrm{mg} \cdot \mathrm{dm}^{-3}$ or in a mixture of SA, $\mathrm{GA}_{3}$, BAP, JA resulted in an increased rate of germination. The positive effect of $\mathrm{GA}_{3}$ application during this process was clearly visible in all examined cultivars. Apple seeds stratified in the presence of jasmonic acid increased not only their germinability but also their rate of germination by 5-10 days in comparison to control seeds (Fig. 2). Yildiz et al. (2007) also demonstrated that jasmonic acid not only increased the germination level of apple seeds, but also accelerated the germination of dormant seeds compared to control. Stratification in the mixture of growth regulators' solutions did not give an additive affect in comparison to the $\mathrm{GA}_{3}$ treatment. Presumably, the concentration of each plant growth regulator in a mixture should be optimized. Lewak (2011) postulated that all growth regulators act collectively as a regulatory complex controlling the course of dormancy elimination. There are three distinct phases during this course characterized by different hormonal balance. Around the 30th and 40th days of stratification, a sharp rise in gibberellins, cytokinins, and JA levels is observed, and at this period of seeds stratification the contents of these growth regulators reached a maximum. It seems that the main obstacle is to evaluate the exact time and concentration of all growth regulators in breaking full dormancy and accelerate this process.

Positive effect of growth regulators applied during stratification was obvious not only for seeds germination but also after 3 months of seedlings' growth in multi-pots (Fig. 3). It concerned all the examined cultivars. Application of $\mathrm{GA}_{3}$ or mixture of SA, GA 3 , BAP, JA were most effective. These results are consistent with other findings where gibberellin treatment accelerated cotyledon greening as well as stimulated the growth of roots (Bulard 1985).

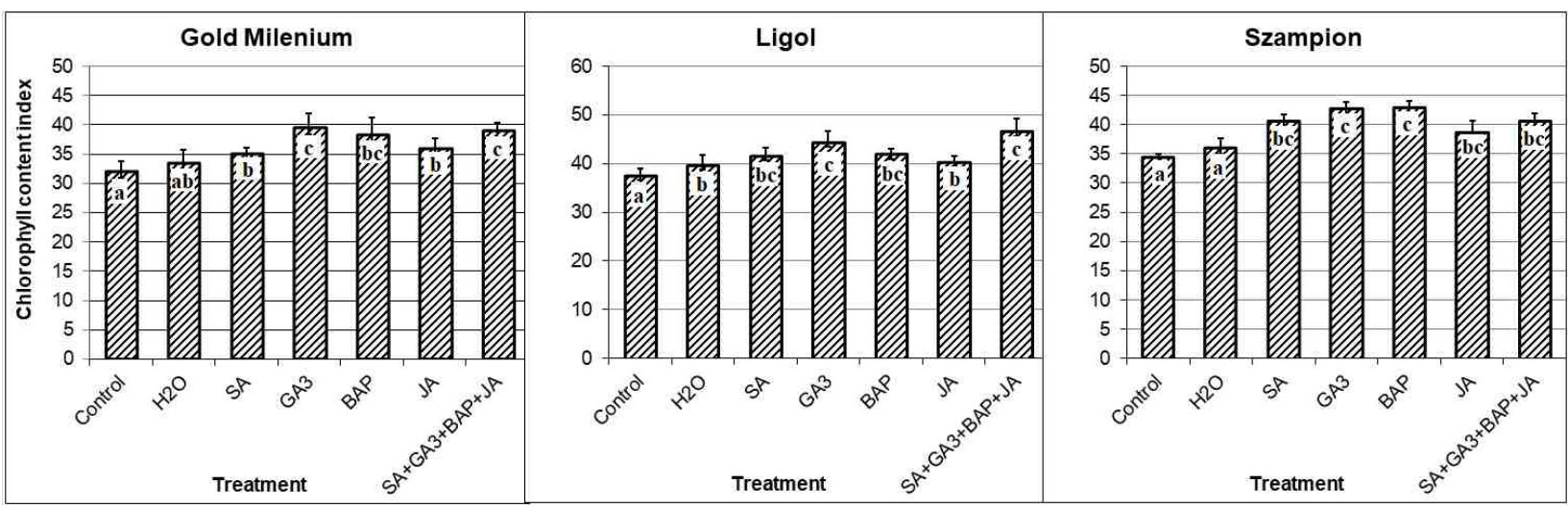

Fig. 4. Chlorophyll content index in leaves of apple seedlings delivered from seeds stratified on filter paper moistened with water or an aqueous solution of salicylic acid $(\mathrm{SA} ; 500 \mathrm{mM})$, jasmonic acid $\left(\mathrm{JA} ; 10^{-3} \mathrm{M}\right)$, gibberellin $\mathrm{A}_{3}\left(\mathrm{GA}_{3} ; 250 \mathrm{mg} \cdot \mathrm{dm}^{-3}\right)$, 6-benzylaminopurine (BAP; $100 \mathrm{mg} \cdot \mathrm{dm}^{-3}$ ) and in their mixture. Means with the same letter are not significantly different at $\mathrm{p}=0.05$ according to the Duncan multiply range test $(\mathrm{n}=30)$. Standard deviation bars are also presented 


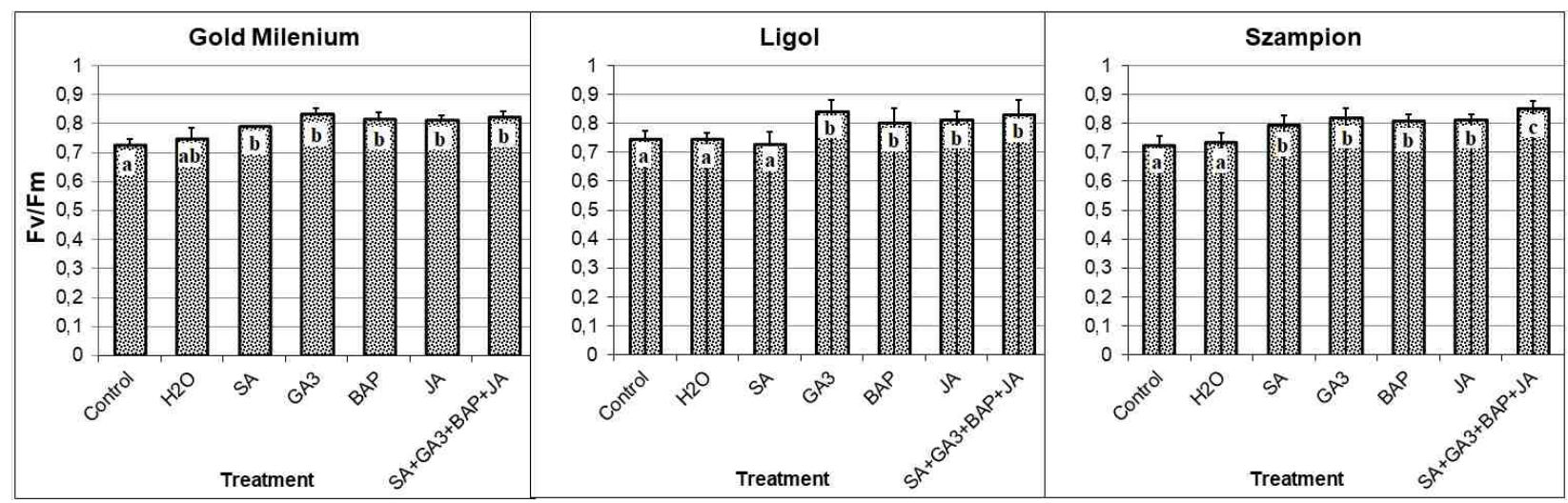

Fig. 5. Maximum PSII efficiency (Fv/Fm) of dark-adapted leaves of apple seedlings delivered from seeds stratified on filter paper moistened with water or an aqueous solution of salicylic acid (SA; $500 \mathrm{mM}$ ), jasmonic acid (JA; $10^{-3} \mathrm{M}$ ), gibberellin $\mathrm{A}_{3}\left(\mathrm{GA}_{3} ; 250 \mathrm{mg} \cdot \mathrm{dm}^{-3}\right)$, 6-benzylaminopurine (BAP; $100 \mathrm{mg} \cdot \mathrm{dm}^{-3}$ ) and in their mixture. Means with the same letter are not significantly different at $\mathrm{p}=0.05$ according to the Duncan multiply range test $(n=30)$. Standard deviation bars are also presented

Apple seeds stratification in water or in growth regulators also affected the chlorophyll contents in leaves expressed by chlorophyll content index (CCI) (Fig. 4). The most pronounced results were obtained after stratification in $\mathrm{GA}_{3}$ or in a mixture of SA, GA, BAP, JA.

Dobránszki and Mendler-Drienyovszki (2014) indicated that the aromatic cytokinins applied in the medium affected the chlorophyll content of the leaves in vitro apple shoots. Lewak (2011) reported that single application of $\mathrm{GA}_{3}$ or cytokinin was without effect in dormant apple embryos. However, the treatment with a mixture of both hormones increased the chlorophyll content up to the level observed in the non-dormant control embryos, which indicated a synergistic effect of both hormones.

Chlorophyll fluorescence measurement is a useful, non-invasive and rapid tool for examining the photosynthetic efficiency of plants and the detection of changes in PSII (Dobránszki \& MendlerDrienyovszki 2014). One of the important challenges to research in this field is to stimulate photosynthetic system. In the present study, seed stratification in distilled water did not sufficiently stimulate the maximum quantum efficiency of Photosystem II (Fv/Fm) of dark-adapted leaves (Fig. 5). However, the inclusion of phytohormones during stratification revealed a significant enhancement of this parameter. The most enhanced results were observed after the application of the mixture of SA, $\mathrm{GA}_{3}$, BAP, JA in 'Szampion' seeds, suggesting that increased photosynthetic efficiency could be attributed to its stimulatory effects on enzymes of Calvin cycle, chlorophyll, expression of photosynthetic genes as well as pigments content (Janda et al. 1998; Xia et al. 2009). Janda et al. (2014) concluded that the effects of phytohormones on the photosynthesis are indirect, originating from their influence on stomatal conductivity. Dobránszki and MendlerDrienyovszki (2014) also reported that the performance of photosynthetic apparatus measured by chlorophyll fluorescence in the leaves in vitro apple shoots was modified by the cytokinin supply.

Application of SA, GA 3 , BAP, JA during the stratification of apple seeds explicitly promoted dormancy removal, which indicated that they are involved in this process. The present study indicates that the application of $\mathrm{GA}_{3}$ or a mixture of $\mathrm{SA}, \mathrm{GA}_{3}$, BAP, JA can be used as an effective method to increase the percentage of seed germination, shorten the period of their germination and juvenile growth of apple seedlings, as well as to improve chlorophyll content index and maximum PSII efficiency $(\mathrm{Fv} / \mathrm{Fm})$. Further studies are needed to optimize the appropriate concentration of growth regulators applied in a mixture during stratification.

\section{CONCLUSION}

1. Stratification in water positively affects dormancy removal in 'Gold Milenium', 'Szampion' and 'Ligol' seeds. 
2. Application of $\mathrm{GA}_{3}, \mathrm{BAP}, \mathrm{SA}$ and JA during seed stratification additionally increases the percentage and dynamics of germinated seeds as well as seedlings growth, chlorophyll content index and maximum PSII efficiency ( $\mathrm{Fv} / \mathrm{Fm})$.

3. The most pronounced results can be expected after seed stratification in $\mathrm{GA}_{3}$ or in a mixture of SA, GA 3 , BAP, JA.

\section{Acknowledgments}

The research was carried out under the statutory activity at the Research Institute of Horticulture in Skierniewice. Research topic 7.3.2.

\section{REFERENCES}

Bewley J.D., Black M. 1994. Seeds. Physiology of development and germination. Plenum Press, New York, 445. DOI: $10.1007 / 978-1-4899-1002-8$.

Bulard C. 1985. Intervention by gibberellin and cytokinin in the release of apple embryos from dormancy: a reappraisal. New Phytologist 101(2): 241-249. DOI: 10.1111/j.1469-8137.1985.tb02831.x.

Chitnis V.R., Gao F., Yao Z., Jordan M.C., Park S., Ayele B.T. 2014. After-ripening induced transcriptional changes of hormonal genes in wheat seeds: the cases of brassinosteroids, ethylene, cytokinin and salicylic acid. PLoS ONE 9(1): e87543, 14 p. DOI: 10.1371/journal.pone.0087543.

Dobránszki J., Mendler-Drienyovszki N. 2014. Cytokinin-induced changes in the chlorophyll content and fluorescence of in vitro apple leaves. Journal of Plant Physiology 171(16): 1472-1478. DOI: 10.1016/j.jplph.2014.06.015.

Grzesik M., Romanowska-Duda Z. 2014. Improvements in germination, growth, and metabolic activity of corn seedlings by grain conditioning and root application with Cyanobacteria and microalgae. Polish Journal of Environmental Studies 23: 1147-1153.

Hilhorst H.W.M., Karssen C.M. 1992. Seed dormancy and germination: the role of abscisic acid and gibberellins and the importance of hormone mutants. Plant Growth Regulation 11(3): 225-238. DOI: 10.1007/bf00024561.

Janda T., Gondor O.K., Yordanova R., Szalai G., Pál M. 2014. Salicylic acid and photosynthesis: signalling and effects. Acta Physiologiae Plantarum 36(10): 2537-2546. DOI: 10.1007/s11738-014-1620-y.

Janda T., Szalai G., Antunovics Zs., Ducruet J.-M., Páldi E. 1998. Effects of salicylic acid and related compounds on photosynthetic parameters in young maize (Zea mays L.) plants. In: Garab G. (Eds.), Photosynthesis: Mechanisms and Effects. Springer, Dordrecht, pp. 3869-3872. DOI: 10.1007/978-94011-3953-3_902.

Kamiński W. 1968. Inhibitory effect of apple juice on the germination of apple and cherry seeds and the growth of apple seedlings. Acta Societatis Botanicorum Poloniae 37(1): 173-178. DOI: 10.5586/asbp. 1968.016.

Lewak S. 2011. Metabolic control of embryonic dormancy in apple seed: seven decades of research. Acta Physiologiae Plantarum 33(1): 1-24. DOI: 10.1007/s11738-010-0524-8.

Linkies A., Leubner-Metzger G. 2012. Beyond gibberellins and abscisic acid: how ethylene and jasmonates control seed germination. Plant Cell Reports 31(2): 253-270. DOI: 10.1007/s00299-011-1180-1.

Ranjan R., Lewak S. 1992. Jasmonic acid promotes germination and lipase activity in non-stratified apple embryos. Physiologia Plantarum 86(2): 335-339. DOI: 10.1034/j.1399-3054.1992.860222.x.

Ranjan R., Lewak S. 1994. Interaction of jasmonic acid with some plant growth regulators in the control of apple (Malus domestica) embryo germination. Plant Growth Regulation 14(2): 159-166. DOI: 10.1007/bf00025218.

Røen D. 1994. Prospects for shortening the breeding cycle of apple (Malus x domestica Borkh.) using embryo culture. I. Reducing the period of cold treatment by hormone application. Gartenbauwissenschaft 59: 49-53.

Rudnicki R. 1969. Studies on abscisic acid in apple seeds. Planta 86: 63-68. DOI: 10.1007/bf00385304.

Sansavini S., Belfanti E., Costa F., Donati F. 2005. European apple breeding programs turn to biotechnology. Chronica Horticulturae 45(2): 16-19.

Seeley S.D., Damavandy H. 1985. Response of seed of seven deciduous fruits to stratification temperatures and implications for modeling. Journal of the American Society for Horticultural Science 110: 726-729.

Sińska I. 1989. Interaction of ethephon with cytokinin and gibberellin during the removal of apple seed dormancy and germination of embryos. Plant Science 64(1): 39-44. DOI: 10.1016/01689452(89)90149-0.

Wyzińska D. 1978. Morphological aspects of apple seedling early development in relation to embryonal dormancy. Biologia Plantarum 20(1): 53-60. DOI: $10.1007 / \mathrm{bf02922929.}$ 
Xia X.J., Huang L.F., Zhou Y.H., Mao W.H., Shi K., Wu J.X. et al. 2009. Brassinosteroids promote photosynthesis and growth by enhancing activation of Rubisco and expression of photosynthetic genes in Cucumis sativus. Planta 230(6): 1185-1196. DOI: 10.1007/s00425-009-1016-1.

Yildiz K., Yazici C., Muradoglu F. 2007. Effect of jasmonic acid on germination dormant and nondormant apple seeds. Asian Journal of Chemistry 19(2): 1098-1102.
Zhang Y.X., Lespinasse Y. 1991. Removal of embryonic dormancy in apple (Malus $\times$ domestica Borkh) by 6-benzylaminopurine. Scientia Horticulturae 46(34): 215-223. DOI: 10.1016/0304-4238(91)90044-y.

Żarska-Maciejewska B., Lewak S. 1976. The role of lipases in the removal of dormancy in apple seeds. Planta 132(2): 177-181. DOI: 10.1007/bf00388900. 